\title{
DIABETIC EFFECTS OF POLYHERBAL FORMULATION OF LAWSONIA INERMIS AND AZADIRACHTA INDICA
}

\author{
"Sonam Rajwar, Pankaj Khatri \\ Department of Pharmacognosy, Gyan Vihar School of Pharmacy, Suresh Gyan Vihar University, Jagatpura, Jaipur- \\ 302025, Rajasthan, India.
}

*Corresponding Author’s Email: sonamrajwar@gmail.com

\begin{abstract}
:
The Present investigation was undertaken to evaluate the Polyherbal Formulation of Lawsonia inermis and Azadirachta indica in Alloxan \& Streptozocin induced diabetic rats. In Alloxan induced diabetic studies samples were collected at $0,2^{\text {nd }}, 5^{\text {th }}, 7^{\text {th }}$ and $10^{\text {th }}$ day after the rats had undervent the hyperglycaemic condition. The results showed that the Polyherbal formulation of Lawsonia inermis and Azadirachta indica (F1, F2, F3) found to be significant decrease $(\mathrm{P}<0.01)$ in blood glucose level as compared to the diabe'/tic control group of animals while F4 \& F5 were not significant $(\mathrm{P}>0.01)$ compared to the diabetic control group of animals. Streptozocin induced diabetic studies evaluates the Blood glucose level and the Diabetic body weight parameters over a period of fourteen days after treatment with Polyherbal Formulation of Lawsonia inermis and Azadirachta indica. On the day 21 the animals treated with Glimiperide drug $(1 \mathrm{mg} / \mathrm{Kg}), \mathrm{F} 1, \mathrm{~F} 2, \mathrm{~F} 3, \mathrm{~F} 4$, F5 were observed with significant increase in their body weight as compared to Diabetic control group of animals and also showed significant decrease $(\mathrm{P}<0.01)$ in Blood glucose level compared to the Diabetic control group.

Key Words: Diabetes, Lawsonia inermis, Azadirachta indica, Streptozocin, Alloxan
\end{abstract}

\section{INTRODUCTION}

Lawsonia inermis, commonly called as Henna and the synonym is Lawsonia alba Linn. belongs to family Lythraceae $^{1}$. It is indigeneous to Africa and is largely cultivated in Egypt, Sudan, Carribean islands, Florida, India and China ${ }^{2}$. The principal colouring matter of henna is lawsone, 2-hydroxy-1:4 napthaquinone besides lawsone other constituents present are gallic acid, glucose, mannitol, fats, resin $(2 \%)$, mucilage and traces of an alkaloid. Leaves yield hennatannic acid and an olive oil green resin, soluble in ether and alcohol. Flowers yield an essential oil (0.01-0.02\%) consist mainly of $\alpha$ - and $\beta$ ionones; a nitrogenous compound and resin. Seeds contain proteins $(5.0 \%)$, carbohydrates $(33.62 \%)$, fibers $(33.5 \%)$, fatty oils (10-11\%) composed of behenic acid, arachidic acid, stearic acid, palmitic acid, oleic acid and linoleic acid $^{3}$. Lawsonia inermis leaves (mehendi) are very popular natural dye to finger, color hand, nails and hair ${ }^{4}$. As a medicinal plant, henna has been used for astringent, anti hemorrhagic, intestinal antineoplastic, cardio-inhibitory, hypertensive and sedative effects and used as a folk remedy against amoebiasis, headache jaundice and leprosy ${ }^{5}$.

Azadirachta indica A. Juss (syn. Melia azadirachta), is popularly known as Indian neem (margosa tree) or Indian lilac $^{6}$. It is a versatile tree native to South and South-East Asia, Japan, tropical USA, South America, Australia and Africa $^{7}$. Biologically active principles isolated from different parts of the plant include: azadiractin, meliacin, gedunin, salanin, nimbin, valassin and many other derivatives of these principles, Meliacin forms the bitter principles of neem seed oil; the seed also contain tignic acid (5-methyl-2-butanic acid) responsible for the distinctive odour of the oil. These compounds belong to natural products called triterpenoids (Limonoids). It possess maximum useful non-wood products such as leaves, bark, flowers fruits, seeds, gum, oil and neem cake than any other species. It is known to have antiallergenic, antidermatic, antifeedant, antiviral, antifungal, antiinflammatory, antipyorrhoeic, antiscabic insecticidal, larvicidal, anti-implantation, nermaticidal, spermatocidal and other biological activities ${ }^{8}$.

Diabetes mellitus (DM) is a group of metabolic diseases characterized by hyperglycaemia, hypertriglyceridaemia and hypercholesterolaemia, resulting from defects in insulin secretion or action or both ${ }^{10}$. It is the world's largest endocrine disease, according to the WHO projections, the prevalence of diabetes is likely to increase by $35 \%$. Statistical projections about India suggest that the number of diabetics will rise from 15 million in 1995 to 57 million in the year of 2025 making it the country with the highest number of diabetics in the world ${ }^{9}$.

Symptoms of Diabetes mellitus are polyuria, polydipsia, losing weight without trying, blurry vision, Frequent infections- including skin infections, thrush, gingivitis, urinary tract infections and yeast infections, Slow healing of sores, Skin problems, such as itchiness or acanthosis Nigricans, Dizziness or fainting ${ }^{11}$. Two groups of oral hypoglycaemic drugs, sulphonylureas and biguanides, have been used in the treatment of Diabetes mellitus ${ }^{10}$. Common side effects of Synthetic drugs are Hypoglycaemia, Nausea, Vomiting, Diarrhoea, Constipation, Headache, Anorexia ${ }^{12}$. While our herbal drugs are also stand for the treatment of Diabetes mellitus with less or no unwanted effects as compare to synthetic diabetic medicines. Some herbal antidiabetic drugs are Achillea ligutica, Aegles marmelos, Andrographis paniculata, Azadirachta indica etc. ${ }^{13}$ It is very important to 
investigate the derived from natural products, which were used in traditional system of medicines for the treatment of diabetes mellitus so hypoglycemic agent have focused on plants which are used in traditional system of medicines because they may be better treatment than synthetic drugs which are available in market ${ }^{18}$. The present research article deals with the aim of evaluating the combined effects of Formulation of Lawsonia inermis and Azadirachta indica leaves extract on blood glucose level, body weight in alloxan diabetic and streptozocin diabetic rats.

\section{MATERIAL AND METHOD}

Plant materials: The Leaves of Lawsonia inermis and Azadirachta indica were collected from the local areas of Jaipur, Rajasthan during April and October 2011 respectively and were authenticated by Mr. Vinod Kumar Sharma, Department of Botany, Rajasthan University Jaipur, Rajasthan. Voucher specimen were deposited in the departmental herbarium of Rajasthan University, Jaipur, India for future reference.

Chemicals: Glibenclamide Tablet (5mg) was purchased from Aventis Pharma, Alloxan was purchased from Central drug house, Glimiperide Tablet (5mg) was purchased from Aventis Pharma, Streptozotocin was purchased from Sigma chemicals, Gum acacia was purchased from Central drug house, Normal saline was purchased from Central drug house, Glucose was purchased from Central drug house, Digital Display Glucometer was purchased from Johnson \& Johnson.

\section{Polyherbal Formulation:}

\subsection{Preparation of Extract of Lawsonia inermis by Hot} Continuous Extraction Method ${ }^{14,15}$ :

Fresh leaves of Lawsonia inermis was collected from the local area of Jaipur, were washed in tap water and then left to dry at room temperature for 2-3 days. The dried leaves were then ground to fine powder in a mixer. A Total of $250 \mathrm{gm}$ of shade dried and powdered leaves of Lawsonia inermis was used for the analysis. Powdered plant material was subjected to extraction with petroleum ether in a soxhlet apparatus. The extraction was continued till the defatting of the plant material had completely done. The deffated marc was extracted successively with aqueous ethanol by soxhlet apparatus. The extraction was carried out until the drug becomes exhausted. The solvents were recovered from their extract by distillation under reduced pressure. The solvent was dried and concentrated using Rotary evaporator at $65^{\circ} \mathrm{C}$. The extract was than analysed by thin layer chromatography to isolate the phytoconstituents responsible for diabetic activity. The solvent system used was butanol: acetic acid: water (6: 2: 1) and the extract was also further analysed by High Performance Liquid Chromatography.

\subsection{Preparation of Extract of Azadirachta indica by Hot Continuous Extraction Method ${ }^{16,17}$ :}

The Azadirachta indica leaves was collected from the local area of Jaipur, cleaned, dried and powdered in a grindermixer to obtain a coarse powder and then passed through 40 mesh sieve. A Total of $250 \mathrm{gm}$ of shade dried and powdered leaves of Azadirahcta indica was used for the analysis.Powdered plant material was subjected to extraction with petroleum ether in a soxhlet apparatus. The extraction was continued till the defatting of the plant material had completely done. The deffated marc of the drugs was subjected to extraction with $70 \%$ ethanol in a Soxhlet apparatus. The extraction was carried out until the drug becomes exhausted. The Ethanolic extract was concentrate at $65^{\circ} \mathrm{C}$ by a rotavapor ${ }^{16,17}$. The extract was than analysed by thin layer chromatography to isolate the phytoconstituents responsible for diabetic activity. The solvent system used was Hexane: ethylacetate (3:7), Chloroform: methanol (97:3), Benzene: acetic acid: water (125: 72: 3) and the extract was also further analysed by High Performance Liquid Chromatography.

\subsection{Polyherbal formulations of Lawsonia inermis and Azadirachta indica extract:-}

The extracts obtained after concentrating by a rotavapor at $65^{\circ} \mathrm{C}$ were dried to obtain a powder. Now the polyherbal formulation of Lawsonia inermis and Azadirachta indica with various concentrate gradients were developed as shown in Table no-1 which was than further analysed for Phytochemical and Pharmacological studies.

Table 1: Effect of F1, F2, F3, F4 \& F5 on alloxan induced diabetic rats

[** Extremely sigmificant $(P<0.01), *$ Significant $(p<0.05), n s-$ Not significant $(P>0.05)]$

\begin{tabular}{|c|c|c|c|c|}
\hline \multirow{2}{*}{$\begin{array}{l}\text { Treatment and Dose } \\
(\mathrm{mg} / \mathrm{kg} \mathrm{p.} \mathrm{o})\end{array}$} & \multicolumn{4}{|c|}{ Serum glucose level (mg/dl) } \\
\hline & O day & 2 nd day & $5^{\text {th }}$ day & $10^{\text {th }}$ day \\
\hline Control Group & $266.48 \pm 3.73$ & $269.16 \pm 3.15$ & $265.33 \pm 3.76$ & $268.29 \pm 2.41$ \\
\hline $\begin{array}{c}\text { Reference Group } \\
\text { (Glibenclamide) }\end{array}$ & $263.06 \pm 3.58$ & $224.00 \pm 2.91$ & $210.76 \pm 4.59$ & $182.66 \pm 1.72$ \\
\hline F1 * & $289.83 \pm 2.34$ & $250.41 \pm 3.22$ & $233.18 \pm 2.63$ & $200.86 \pm 3.45$ \\
\hline F2* & $288.54 \pm 2.79$ & $251.77 \pm 4.52$ & $236.58 \pm 3.04$ & $215.73 \pm 2.89$ \\
\hline F3* & $286.38 \pm 1.84$ & $256.25 \pm 3.28$ & $240.23 \pm 0.59$ & $222.35 \pm 2.25$ \\
\hline F4 ns & $265.74 \pm 3.92$ & $261.03 \pm 2.35$ & $260.56 \pm 3.29$ & $246.17 \pm 4.48$ \\
\hline F5 ns & $270.15 \pm 3.88$ & $265.72 \pm 2.46$ & $260.19 \pm 3.08$ & $252.79 \pm 2.81$ \\
\hline
\end{tabular}


2 Pharmacological antidiabetic study of Polyherbal formulation of Lawsonia inermis and Azadirachta indica:-

2.1 Alloxan Induced Diabetes ${ }^{18}$ : D.Ray et al., 2006. ( Full reference of Alloxan)

Animals:- Albino wistar male rats weighing 150-200g was used for the present study. They were maintained in the animal house of Gyan Vihar Shool of Pharmacy for experimental purpose. The animals were maintained under controlled conditions of temperature $\left(23 \pm 2{ }^{\circ} \mathrm{C}\right)$, humidity $(50 \pm 5 \%)$ and 12 -h light-dark cycles. All the animals were acclimatized for seven days before the study. The animals were randomized into experimental and control groups and housed individually in sanitized polypropylene cages containing sterile paddy husk as bedding. They had free access to standard pellets as basal diet and water ad libitum. Animals were habituated to laboratory conditions for 48 hours prior to experimental protocol to minimize if any of non-specific stress. All the studies conducted were approved by the Institutional Animal Ethical Committee (IAEC) of Gyan Vihar School of Pharmacy. According to prescribed guidelines of Committee for the Purpose of Control and Supervision of Experiments on Animals (CPCSEA), Government of India. We selected male animals for all our studies, since females are shown to be protected from changes in lipid-induced insulin action.

\section{Induction of Experimental Diabetes:-}

The acclimatized animals were kept fasting for 24 hours with water ad libitum and injected intraperitonially a dose of $120 \mathrm{mg} / \mathrm{kg}$ of alloxan mono hydrate in normal saline. After one hour, the animals were provided standard laboratory diet ad libitum. The blood glucose level was checked before alloxanisation and 24 hour after alloxanisation by withdrawing blood from the tip of the tail of each rat under anaesthesia. The blood glucose level was measured as above. Animals were considered diabetic when the blood glucose level was raised beyond $225 \mathrm{mg} / \mathrm{dl}$. This condition was observed at the end of $48 \mathrm{hrs}$ after Alloxanisation.

\section{Experimental Procedure:-}

Forty Two albino rats weighing 150-200g were fasted for $24 \mathrm{hr}$ and were divided into Seven groups of six animals in each. The groups included:

\section{1) Group I : as Vehicle received 5\%} gum acacia in normal saline, $1 \mathrm{ml} / 200 \mathrm{~g}$ rat.

2) Group II (F1) : received $1 \mathrm{ml} / \mathrm{rat}$ p.o .

$\begin{array}{lll}\text { 3) Group III (F2) } & \text { : } & \text { received } 1 \mathrm{ml} / \text { rat p.o . } \\ \text { 4) Group IV (F3) } & \text { : } & \text { received } 1 \mathrm{ml} / \text { rat p.o . }\end{array}$

5) Group V (F4) : received $1 \mathrm{ml} /$ rat p.o .

\section{6) Group VI (F5) : received $1 \mathrm{ml} / \mathrm{rat}$ p.o \\ 7) Group VII $\quad$ : as Standard received}

Glibenclamide $(0.5 \mathrm{mg} / \mathrm{kg}$ p.o. $10 \% \mathrm{w} / \mathrm{v}, 1 \mathrm{ml} / 200 \mathrm{~g}$ rat $)$.

One milliliter of blood from the tail of each rat was collected at ' 0 ' day. Than at 2 nd day, 5 th day and 10 th day subsequently, blood samples were collected again from the treated animals and blood glucose was estimated by digital display glucometer.

\section{Statistical Analysis:-}

Results are expressed as mean \pm SD. The differences between experimental groups were compared by one-way Analysis of Variance (ANOVA) followed by Bonferroni's test. The results were considered statistically significant when $\mathrm{P}<0.05$. (Table 1)

\subsection{Streptozotocin Induced Diabetes ${ }^{18}$}

Animals:- Albino wistar male rats weighing 150-200g was used for the present study. They were maintained in the animal house of Gyan Vihar School of Pharmacy for experimental purpose. The animals were maintained under controlled conditions of temperature $\left(23 \pm 2^{\circ} \mathrm{C}\right)$, humidity $(50 \pm 5 \%)$ and 12-h light-dark cycles. All the animals were acclimatized for seven days before the study. The animals were randomized into experimental and control groups and housed individually in sanitized polypropylene cages containing sterile paddy husk as bedding. They had free access to standard pellets as basal diet and water ad libitum. Animals were habituated to laboratory conditions for 48 hours prior to experimental protocol to minimize if any of non-specific stress. All the studies conducted were approved by the Institutional Animal Ethical Committee (IAEC) of Gyan Vihar School of Pharmacy. According to prescribed guidelines of Committee for the Purpose of Control and Supervision of Experiments on Animals (CPCSEA), Government of India. We selected male animals for all our studies, since females are shown to be protected from changes in lipid-induced insulin action.

\section{Induction of Experimental Diabetes:-}

Healthy Wistar strain albino rats of either sex weighing about 150-200 grams were taken. Animals were deprived to food for 16 hours but allowed free access to water after that blood sample was collected from tail of rats and measure blood glucose level by using digital display glucometer. Then they were injected with streptozotocin dissolved in $0.1 \mathrm{M}$ sodium citrate and citric acid at a dose of $60 \mathrm{mg} / \mathrm{kg}$ body weight intraperitoneally. Then animals were kept for 21 days during which food and water was allowed. After 7 and 21days of streptozotocin administration blood glucose level, body weight, grip strength and pain sensation measurements were taken. The animals showed fasting blood glucose level above 250 $\mathrm{mg} / \mathrm{dl}$ considered diabetic after that they were divided into seven groups in which each group contain six animals. After that the administered control, standard and test drug orally. The blood glucose level, body weight, of each rat were taken weekly after oral administration of drug/extracts. The mean values of these parameters were taken for each group and compared with the value of standard drug.

Estimation of Body Weight: 
Diabetic animals show reduction in body weight hence body weight of all the animals measured every week till the completion of study.

\section{Estimation of Blood Glucose level:}

The blood samples were collected from rat-tail vein on day before injecting the streptozotocin and on subsequent 7and 21 days after injection of streptozotocin for estimation of blood glucose level. The blood glucose estimation was done weekly after administration of test compounds, with the help of glucometer. (Table 2)

\section{Statistical Analysis:-}

Statistical analysis was carried out as per standard method. All results were expressed as mean \pm S.D. Groups of data were compared with the analysis of variance (ANOVA) followed by Dunnett's t-test values for statistical significance $\mathrm{P}>0.01$ was considered significant. (Table 3 )

\section{RESULTS}

Effect of Alloxan on blood glucose level:

As the Hypoglycemic activity of F1 to F5 was studied both in normal and alloxan induced diabetic rats, it was observed that F1, F2, F3 found to be significant decrease $(\mathrm{P}<0.01)$ in blood glucose level, while F4 \& F5 were not significant $(\mathrm{P}>0.01)$.

\section{Effect of Streptozotocin on body weight and blood glucose level:}

The body weight decreased rapidly in STZ treated diabetic rats and the blood glucose levels increased rapidly after STZ injection. The present study evaluates Diabetes and Diabetic Body Weight parameters over a period of fourteen days after treatment with Polyherbal formulation of Lawsonia inermis and Azadirachta indica.

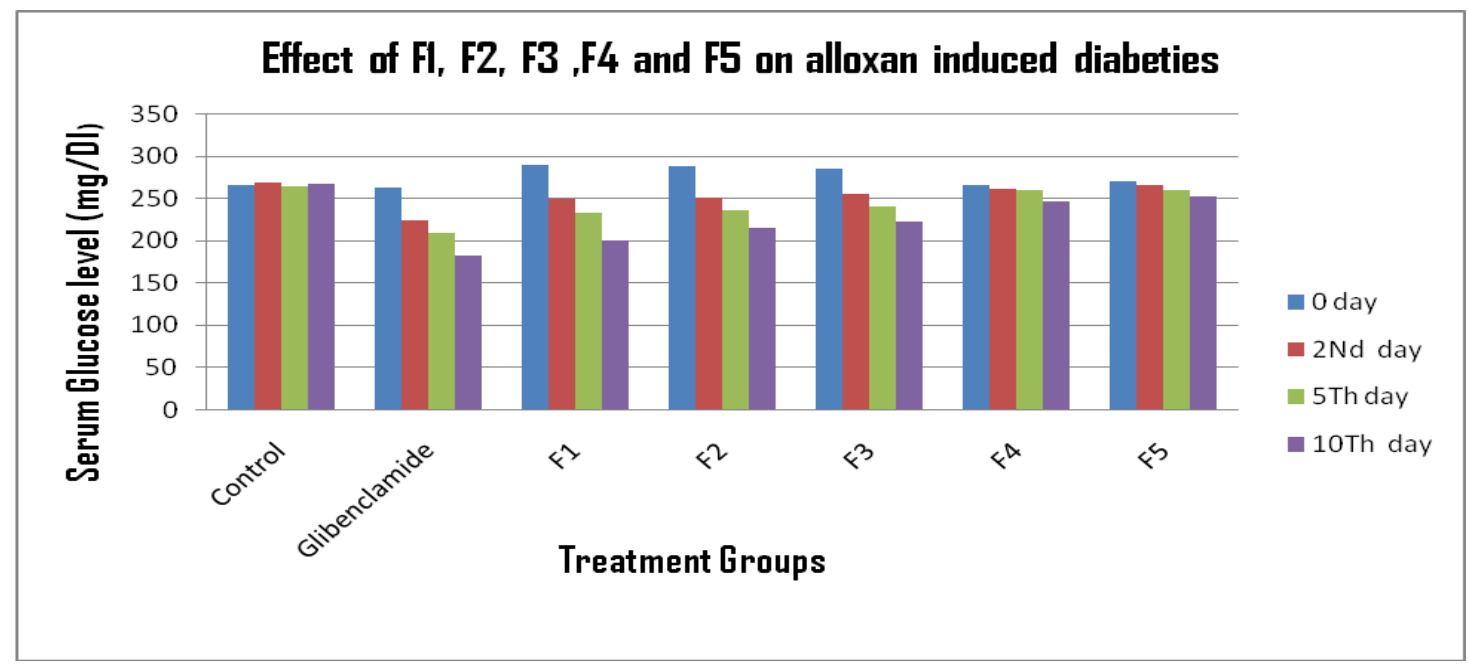

Figure 1: Effet of F1, F2, F3, F4 \& F5 on alloxan induced diabetic rats

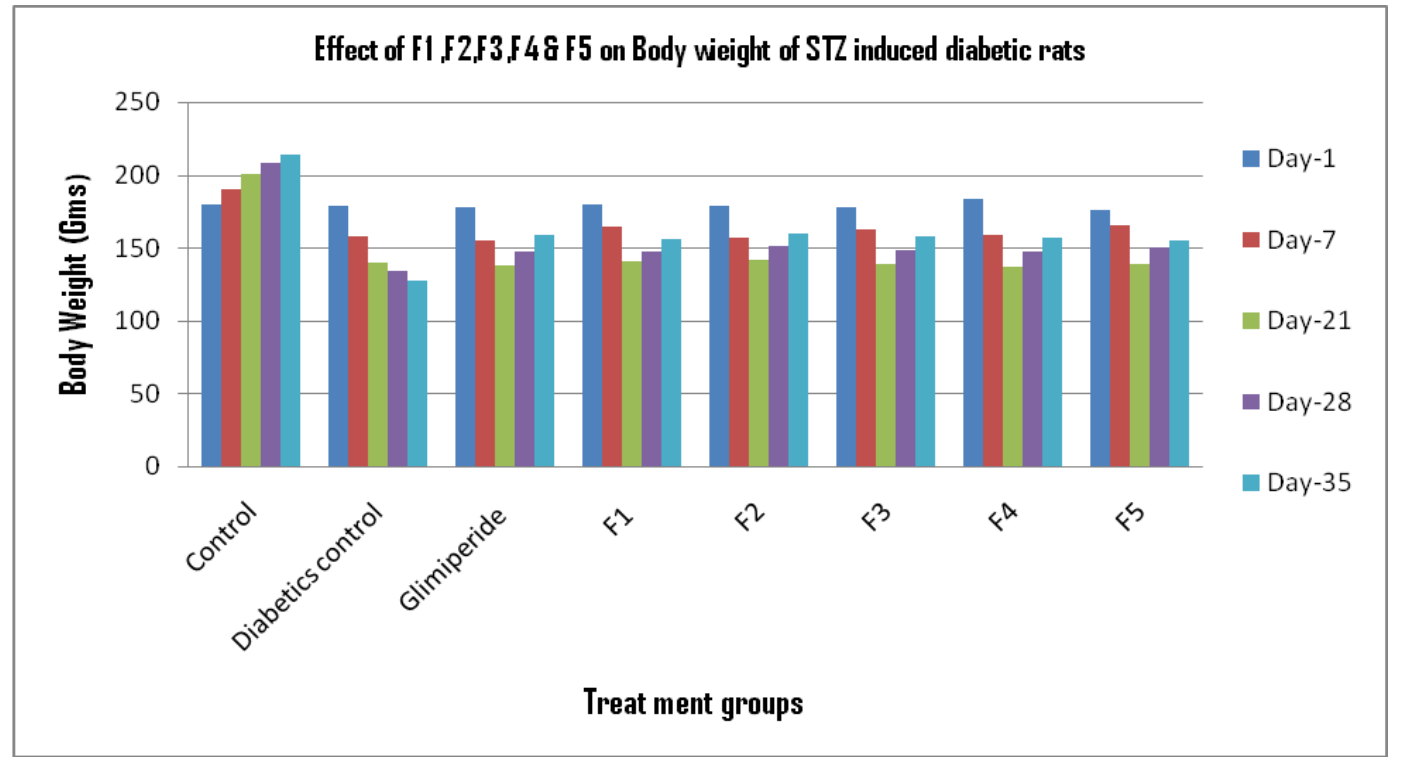

Figure 2: Effect of F1, F2, F3, F4 and F5 on body weight of SZT-induced diabetic rats 
Table 2: Polyherbal Formulation of Lawsonia inermis and Azadirachta indica

\begin{tabular}{|c|c|c|c|}
\hline S.No. & Formulation & Lawsonia inermis & Azadirachta indica \\
\hline 1 & $\mathrm{~F}_{1}$ & $10 \mathrm{gm}$ & $0 \mathrm{gm}$ \\
\hline 2 & $\mathrm{~F}_{2}$ & $7.5 \mathrm{gm}$ & $2.5 \mathrm{gm}$ \\
\hline 3 & $\mathrm{~F}_{3}$ & $50 \mathrm{gm}$ & $50 \mathrm{gm}$ \\
\hline 4 & $\mathrm{~F}_{4}$ & $2.5 \mathrm{gm}$ & $7.5 \mathrm{gm}$ \\
\hline 5 & $\mathrm{~F}_{5}$ & $0 \mathrm{gm}$ & $10 \mathrm{gm}$ \\
\hline
\end{tabular}

Table 3: The effect of F1, F2, F3, F4 and F5 on body weight of SZT-induced diabetic rats

\begin{tabular}{|l|c|c|c|c|c|}
\hline \multirow{2}{*}{ Groups } & \multicolumn{5}{|c|}{ Change in body weight on different days } \\
\cline { 2 - 6 } & Day-1 & Day-7 & Day-21 & Day-28 & Day-35 \\
\hline Control & $180.33 \pm 7.65$ & $190.33 \pm 11.69$ & $201.66 \pm 13.66$ & $208.33 \pm 10.80$ & $214.16 \pm 10.20$ \\
\hline $\begin{array}{l}\text { Diabetics } \\
\text { control }\end{array}$ & $179.5 \pm 5.54$ & $158.83 \pm 5.84^{* * *}$ & $140.00 \pm 7.74^{* * *}$ & $134.50 \pm 7.84^{* * *}$ & $127.16 \pm 7.08^{* * *}$ \\
\hline $\begin{array}{l}\text { Glimiperide } \\
\text { drug(1 mg/kg) }\end{array}$ & $178.16 \pm 7.27$ & $155.83 \pm 7.35^{* * *}$ & $138.83 \pm 10.30^{* * *}$ & $147.00 \pm 7.74^{* * *}$ & $159.50 \pm 7.58^{* * *, a}$ \\
\hline F1 & $180.83 \pm 8.61$ & $164.5 \pm 3.93^{* * *}$ & $141.66 \pm 11.69^{* * *}$ & $147.66 \pm 10.83^{* * *}$ & $156.66 \pm 10.87^{* * *, a}$ \\
\hline F2 & $179.16 \pm 9.70$ & $157.5 \pm 5.00^{* * *}$ & $142.16 \pm 5.11^{* * *}$ & $151.33 \pm 4.54^{* * *}$ & $160.16 \pm 6.96^{* * *, a}$ \\
\hline F3 & $178.83 \pm 3.76$ & $163.33 \pm 8.75^{* * *}$ & $139.66 \pm 9.93^{* * *}$ & $148.00 \pm 9.69^{* * *}$ & $158.16 \pm 9.08^{* * *, a}$ \\
\hline F4 & $183.5 \pm 6.89$ & $159.16 \pm 6.64^{* * *}$ & $137.16 \pm 9.28^{* * *}$ & $147.83 \pm 9.06^{* * *}$ & $157.33 \pm 6.86^{* * *, a}$ \\
\hline F5 & $176.5 \pm 3.65$ & $165 \pm 2.69^{* * *}$ & $139.25 \pm 6.26^{* * *}$ & $150.56 \pm 5.23^{* * *}$ & $155.32 \pm 8.96^{* * *, a}$ \\
\hline
\end{tabular}

Table 4: The effect of F1, F2, F3, F4 and F5 on Blood glucose level of SZT-induced diabetic rats

\begin{tabular}{|l|l|l|l|l|l|}
\hline \multirow{2}{*}{ Groups } & \multicolumn{5}{|c|}{ Change in blood glucose levels on different days } \\
\cline { 2 - 6 } & Day-1 & Day-7 & Day-21 & Day-28 & Day-35 \\
\hline Control & $83.33 \pm 5.50$ & $80.16 \pm 4.35$ & $82 \pm 6.13$ & $82.16 \pm 3.18$ & $83.83 \pm 7.98$ \\
\hline $\begin{array}{l}\text { Diabetic } \\
\text { control }\end{array}$ & $82.66 \pm 5.20$ & $303.33 \pm 10.69^{* * *}$ & $312 \pm 6.32^{* * *}$ & $319.16 \pm 5.98^{* * *}$ & $325.5 \pm 6.56^{* * *}$ \\
\hline $\begin{array}{l}\text { Glimiperide } \\
\text { drug(1 mg/kg) }\end{array}$ & $82.5 \pm 7.36$ & $308 \pm 8.22^{* * *}$ & $316.66 \pm 8.38^{* * *}$ & $81.83 \pm 5.34^{\mathrm{b}, \mathrm{a}^{* * * *}}$ & $82 \pm 5.47^{\mathrm{b}, \mathrm{a}^{* * *}}$ \\
\hline F1 & $82 \pm 5.96$ & $308 \pm 13.74^{* * *}$ & $318.33 \pm 7.22^{* * *}$ & $133.66 \pm 17.96^{* * *, \mathrm{a}^{* * *}}$ & $129.16 \pm 8.08^{* * *, \mathrm{a}^{* * *}}$ \\
\hline F2 & $82 \pm 5.01$ & $302.33 \pm 11.91^{* * *}$ & $313.5 \pm 6.65^{* * *}$ & $123.66 \pm 11.69^{* * *, \mathrm{a}^{* * * * *}}$ & $115.33 \pm 9.62^{* * *, \mathrm{a}^{* * * *}}$ \\
\hline F3 & $83.33 \pm 6.18$ & $305.83 \pm 13.79^{* * *}$ & $318.16 \pm 9.19^{* * *}$ & $121 \pm 9.20^{* * *, \mathrm{a}^{* * *}}$ & $101.66 \pm 6.97^{* *, \mathrm{a}^{* * *}}$ \\
\hline F4 & $81.83 \pm 4.11$ & $310.33 \pm 12.11^{* * *}$ & $319.66 \pm 10.96^{* * *}$ & $108.5 \pm 10.69^{* * *, \mathrm{a}^{* * *}}$ & $90 \pm 7.01^{\mathrm{b}, \mathrm{a}^{* * *}}$ \\
\hline F5 & $86.72 \pm 3.25$ & $299.25 \pm 8.56^{* * *}$ & $309.66 \pm 8.56^{* * *}$ & $152.5 \pm 6.23^{* * *}$ & $103.25 \pm 6.23^{\mathrm{a}^{*}}$ \\
\hline
\end{tabular}

Values are mean $\pm S D, n=6, * *=P<0.01, * * *=P<0.001$ when compared to control group, $b=n$ s when compared to control group, $a^{* * * *}=P<0.001$ when compared to diabetic control group, $c=n s$ when compared to standard group. 


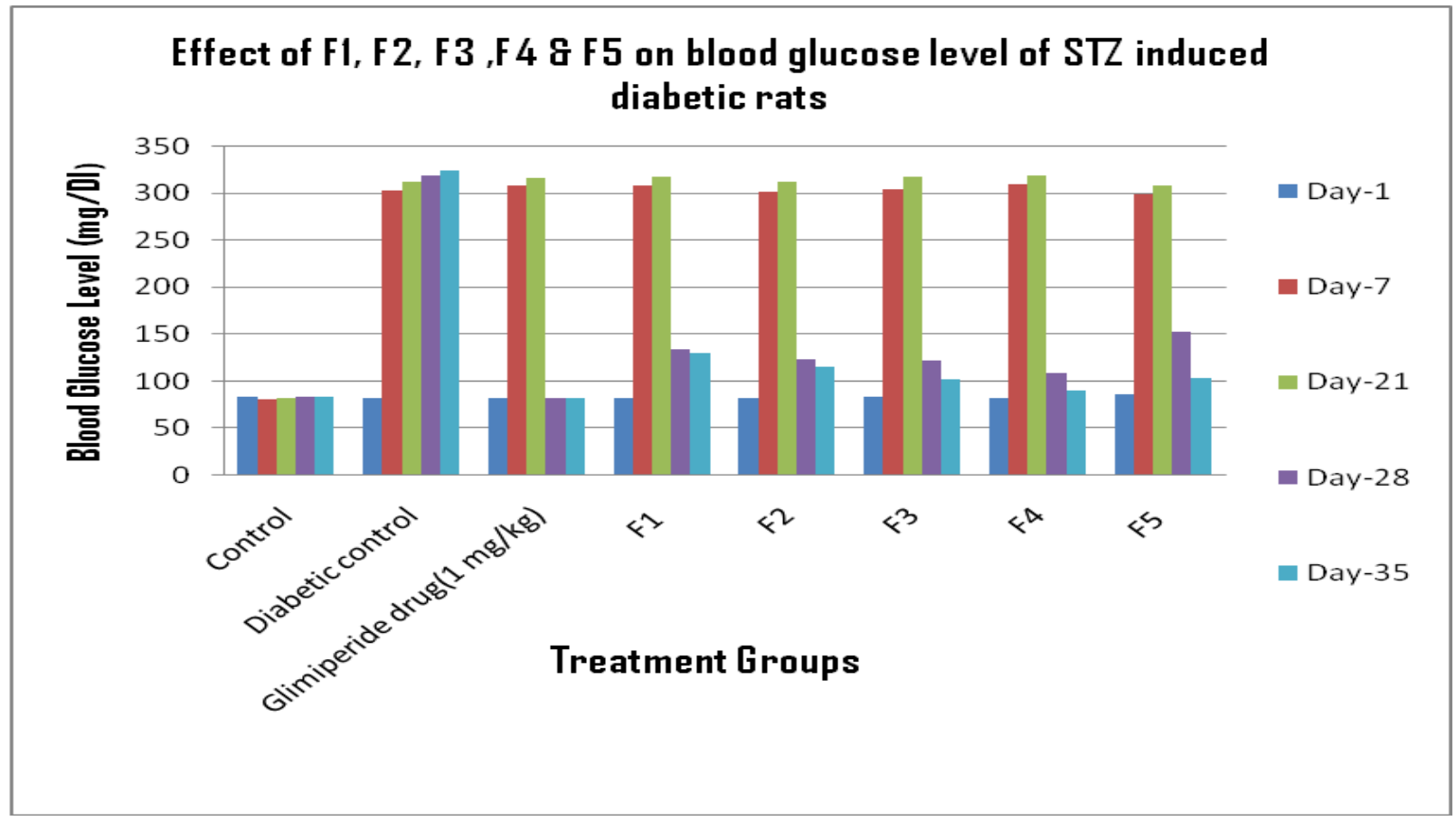

Figure 3: The effect of F1, F2, F3, F4 and F5 on Blood glucose level of SZT-induced diabetic rats

Measurements of body weight of the rats of all experimental groups are shown in table 2 and figure 2. The body weight increased normally in control rats, while STZ induced diabetic rats (Diabetic control) showed a significant decrease in body weight as soon as one week post-STZ injection (Pre: $179.5 \pm 5.54$ to $158.83 \pm 5.84$, $\mathrm{P}<0.01)$. A progressive loss of body weight was noted after 21 days (pre: $179.5 \pm 5.54$ to $140 \pm 7.74, \mathrm{P}<0.001$ ). The maximum decrease in body weight was observed after 5 weeks STZ-injection (pre: $179.5 \pm 5.54$ to $127.16 \pm 7.08$, $\mathrm{P}<0.001)$. The weight of the animals of other groups was also decreased significantly till day 21 as compared to control group (Table 2). On the day 21 the animals treated with Glimiperide drug (1 mg/kg), F1, F2, F3, F4 and F5 were observed with significant increase in their body weight as compared to Diabetic control group of animals.

The blood glucose level of all experimental groups, except control group was increased significantly after the STZ injection till day 21 (Table 3 and Figure 3). In the diabetic group (Diabetic control) the blood glucose levels increased to the maximum measurable value of $325.5 \pm 6.56 \mathrm{mg} / \mathrm{dl}$ on day 35 and found to be significant increased $(\mathrm{P}<0.001)$ compared to the value of day1 was $82.66 \pm 5.20 \mathrm{mg} / \mathrm{dl}$. In contrast, control animals remained normoglycaemic during the entire testing period of 14 days (Table 3 ). The animals treated with glimiperide drug (1 mg/kg), F1, F2, F3, F4 and F5 were observed with significant decrease $(\mathrm{P}<0.001)$ in blood glucose level compared to Diabetic control group.

\section{CONCLUSION}

The results obtained from the present study show that the Polyherbal Formulation of Lawsonia inermis and Azadirachta indica had beneficial effect on blood glucose level in alloxan \& streptozocin induced diabetic rats and also on body weight in streptozocin induced diabetic rats. Lawsonia inermis and Azadirachta indica appears to be useful material for further studies, leading to possible drug development for diabetes as their combined formulation on different concentration gradient had shown the potential role of antidiabetic activity. Further Phytochemical investigations are required to elucidate the exact mechanism of action \& also the active principles responsible for such effects.

\section{ACKNOWLEDGEMENT}

Authors are thankful to Chairman, Chief mentor, Vice Chancellor of Suresh Gyan Vihar University, Jagatpura, Jaipur, Rajasthan for necessary facilities. 


\section{REFERENCES:}

1. M Grieve, www.botanical.com/botanical/mgmh /h/henna24.html (Aprill1,2005).

2. Kokate CK, Porohit AP, Gokhale SB; Pharmacognosy; Nirali Prakashan, 37 edition; Page No. 254.

3. Gagandeep Chaudhary, Sandeep Goyal, Priyanka Poonia; Lawsonia inermis Linnaeus: A Phytopharmacological Review International Journal of Pharmaceutical Sciences and Drug Research 2010; 2(2): 91-98 ISSN 0975-248X.

4. Rosenberg, NM: Antibacterial deodorizing compositions containing extracts of Lawsonia alba. PCT, 1999; 37.

5. Ahmed S, Rahman A, Alam A, Saleem M, Athar M and Sultana S: Evaluation of the efficacy of lawsonia alba in the alleviation of carbon tertrachloride-induced oxidative stress. J Ethnopharm, 2000; 69: 157-164.

6. Kausik Biswas, Ishita Chattopadhyay, Ranajit K. Banerjee and Uday Bandyopadhyay; Biological activities and medicinal properties of neem (Azadirachta indica); Current Science, 2002; 82 (11): 1336-1345.

7. Zoheir.YAshrafi, Sedigheh Sadeghi, Hassan.M.Alizade, Hamid.R.Mashhadi, Ebrahim. R. Mohamadi; Study of Bioassay the Allelopathical Effect of Neem (Azadirachta indica) nhexane, Acetone and Water-soluble Extracts on Six Weeds; International Journal of Biology; 2009; 1(1) ; 71.

8. Ogbuewu IP, Odoemenam VU, Obikaonu HO, Opara MN, Emenalom OO, Uchegbu MC, Okali IC, Esonu BO \& Iloeje MU; The Growing Importance of Neem (Azadirachta indica A. Juss) in Agriculture, Industry, Medicine \& Environment; Research Journal of Medicinal Plant 2011;3(2): 230-245.

9. Chandel HS, Pathak A and Tailang A; Polyherbal Formulations for Anti Diabetic Therapy; Int J Pharm Pharm Sci, 2011, 3(3): 226-228.
10. Tenpe CR and Yeole PG; Comparative evaluation of antidiabetic activity of some marketed polyherbal formulations in alloxan induced diabetic rats; International Journal of PharmTech Research ISSN : 0974-4304 2009; 1(1): 43-43.

11. Samreen Riaz; Diabetes Mellitus; Scientific Research and Essay 2009,4 (5) 367-373.

12. Tripathi KD; Essential of Medical Pharmacology; Fifth edition; Jaypee Brothers Medical Publishers (P) LTD, 248.

13. Kumar $\mathrm{BD}$, Mitra $\mathrm{A}$ and Manjunatha $\mathrm{A}$; In vitro and In vivo studies of antidiabetic Indian Medicinal Plants; Journal of Herbal Medicine and Toxicology 2009; 3 (2): 9-14.

14. Syamsudin, Inawati, and Hendig Winarno; The effect of Inai (Lawsonia inermis Linn) leaves extract on Blood Sugar level: An experimental Study; Research Journal of Pharmacology 2008; 2(2): 20-23, ISSN: 1815-1962.

15. Chaudhary G, Goyall S, Poonia P: Lawsonia inermis Linnaeus: A Phytopharmacological Review International Journal of Pharmaceutical Sciences and Drug Research 2010; 2(2): 91-98 ISSN 0975-248X.

16. Akinola et al. ; Intestinal Lesions of Streptozocin-induced Diabetes and the effects of Azadirachta indica Treatment; Pharmacologyonline 2009; 3(1): 872-881.

17. Bisht S, Sisodia S; Anti-Hyperglycemic And Antidyslipidemic Potential Of Azadirachta indica Leaf Extract In STZ- Induced Diabetes Mellitus; J. Pharm. Sci. \& Res 2010; 2(10): 622-627.

18. Hevener A, Reichart D, Janez A, Olefsky J. Female rats do not exhibit free fatty acid-induced insulin resistance. Diabetes 2007; 51 1907-1912. 